\title{
- Mapa Estratégico de um Curso de Administração
}

\author{
Maria da Graça Pitiá Barreto ${ }^{1}$ \\ Eduardo Fausto Barreto ${ }^{2}$ \\ João Marcelo Pitiá Barreto ${ }^{3}$
}

\section{Resumo}

Parece comum a problemática de planejar um Curso de Administração, elaborar seu projeto pedagógico e implantá-lo com a adequada participação da totalidade do corpo docente. A pergunta norteadora deste estudo é a seguinte: Como fazer a comunidade acadêmica participar da elaboração do projeto pedagógico e compreender-se no contexto institucional da busca do profissional pretendido? $\mathrm{O}$ objetivo que se pretende alcançar com o desenvolvimento deste estudo, é discutir uma metodologia de como se pode promover a discussão do projeto pedagógico de um curso de graduação, integrando toda a comunidade acadêmica, fazendo com que cada docente perceba sua participação na construção do profissional que se pretende formar. Foi realizado um estudo exploratório, descritivo da realidade de uma unidade de uma universidade pública. A estratégia de pesquisa foi um estudo de caso com dados primários da Escola de Administração estudada, em que se buscou adaptar a metodologia da elaboração dos mapas estratégicos desenvolvidos por Kaplan e Norton, às discussões e implantação do projeto pedagógico do Curso de Administração ministrado por essa unidade.

Palavras-chave: Mapa Estratégico. Projeto Pedagógico. Perfil do Profissional pretendido.

\footnotetext{
${ }^{1}$ Doutora e Mestre em Administração pela Universidade Federal da Bahia. Professora-Associada II da Escola de Administração da Universidade Federal da Bahia, Vice-Diretora da Escola de Administração da UFBA, Vice-Presidenta Científica da ANGRAD, Diretora de Formação Profissional do CRA-Ba. Endereço: Universidade Federal da Bahia, Escola de Administração, Departamento de Finanças e Políticas Públicas. Av. Reitor Miguel Calmon, S/N2 . Andar Graça. Salvador, BA. CEP: 40110-100. E-mail: grapitia@ufba.br.

${ }^{2}$ Doutor e Mestre em Administração. Professor-Associado II da UFBA.

- Professor do Programa de Mestrado em Ciências Contábeis da UFBA., Presidente da Câmara de PosGraduação da UFBA. Endereço: Universidade Federal da Bahia, Escola de Administração. Av. Reitor Miguel Calmon Canela-Salvador, BA. CEP: 40100-903 E-mail: eduardofausto@hotmail.com. ${ }^{3}$ Mestre em Contabilidade pela Faculdade de Ciências Contábeis da UFBA., Auditor da PriceWatherhouse. Professor tutor de Curso de Pós-Graduação em Administração Financeira oferecido pela Universidade Federal da Bahia. Endereço: Universidade Federal da Bahia, Escola de Administração, Departamento de Finanças e Políticas Públicas. Av. Reitor Miguel Calmon, S/N 2 . Andar Graça. Salvador, BA. CEP: 40110-100. E-mail: jmpitiab@hotmail.com. Artigo recebido em: 03/09/2008. Aceito em: 26/12/2008. Membro do Corpo Editorial Científico responsável pelo processo editorial: João Nilo Linhares.
} 


\section{Introdução}

Recentemente, as Instituições de Ensino Superior (IES) que ministram cursos de Administração tiveram que ajustar os projetos pedagógicos de seus cursos, seguindo a Resolução CNE/CES n 4, de 13/07/2005, publicada no Diário Oficial da União de 19/07/2005, que institui as Diretrizes Curriculares Nacionais do Curso de Graduação em Administração, bacharelado, e dá outras providências.

O esforço institucional em ajustar o Curso de Administração, não só às exigências regulamentares, como também às mudanças conjunturais, esbarra numa grande dificuldade: fazer todo o corpo docente sentir-se parte integrante do projeto pedagógico elaborado e ter consciência da importância da sua disciplina, ou da atividade coordenada pelo professor, no perfil do profissional projetado.

Quem atua como Diretor Acadêmico de uma Instituição de Ensino ou exerce a função de Coordenação de um Curso conhece a dificuldade de integração de todo o corpo docente não só na elaboração do Projeto Pedagógico, como e principalmente na sua implantação. Quando os avaliadores ad hoc do Ministério da Educação e Cultura (MEC) visitam as IES, no exercício de seu papel por ocasião do processo de autorização, reconhecimento, etc., encontram diferenças entre o que está estabelecido no Projeto Pedagógico e o modo como se pronunciam os professores por ocasião das entrevistas realizadas. Esse testemunho é frequentemente dado em eventos onde se encontram professores que atuam como avaliadores do MEC.

Portanto, parece comum a problemática de planejar um Curso de Administração, elaborar seu projeto pedagógico e implantá-lo com a adequada participação da totalidade do corpo docente. Toda mudança feita sem o debate institucional com todos os integrantes da comunidade acadêmica, pode ter seus resultados comprometidos.

Outro aspecto a ser destacado é a necessidade de buscar a integração de toda a comunidade em torno do projeto pedagógico, como uma equipe cujos componentes trabalhem juntos em busca dos objetivos almejados. Vergara (2000, p. 149) destaca que, para que um grupo de pessoas

[...] se torne uma equipe, é preciso que haja um elemento de identidade, elemento de natureza simbólica que una as pessoas, estando elas fisicamente próximas, ou não. 
Esse elemento de identidade pode ser o perfil do profissional que se deseja formar. É importante que cada integrante da equipe se reconheça comprometido nessa busca.

A pergunta norteadora deste estudo é a seguinte: como fazer a comunidade acadêmica participar da elaboração do projeto pedagógico e entenderse no contexto institucional na busca do profissional pretendido?

Sabe-se que as IES são produtoras do conhecimento, ou melhor, refletem o conhecimento que vai evoluindo na sociedade. Através da pesquisa, as Instituições observam o paradigma estabelecido, comparam com a realidade observada e, a partir daí, promovem a evolução da ciência. Khun (1970) destaca que a ciência avança por rupturas de paradigmas. Segundo esse autor, a partir do paradigma estabelecido, cria-se determinada ciência. Em decorrência da observância de anomalias ou de fatos que não sejam justificados ou explicados pela ciência, é realizado o que o autor denomina de revolução da ciência, através da qual novos paradigmas são testados e aceitos, promovendo a atualização do conhecimento.

A Figura 1 destaca a participação das IES na produção do conhecimento e, também, como usuárias desse conhecimento produzido. Essas instituições precisam ser geridas aplicando o conhecimento produzido, de forma que, com a aplicação dos conhecimentos necessários para uma gestão eficiente, lhes possa ser garantida sua existência.

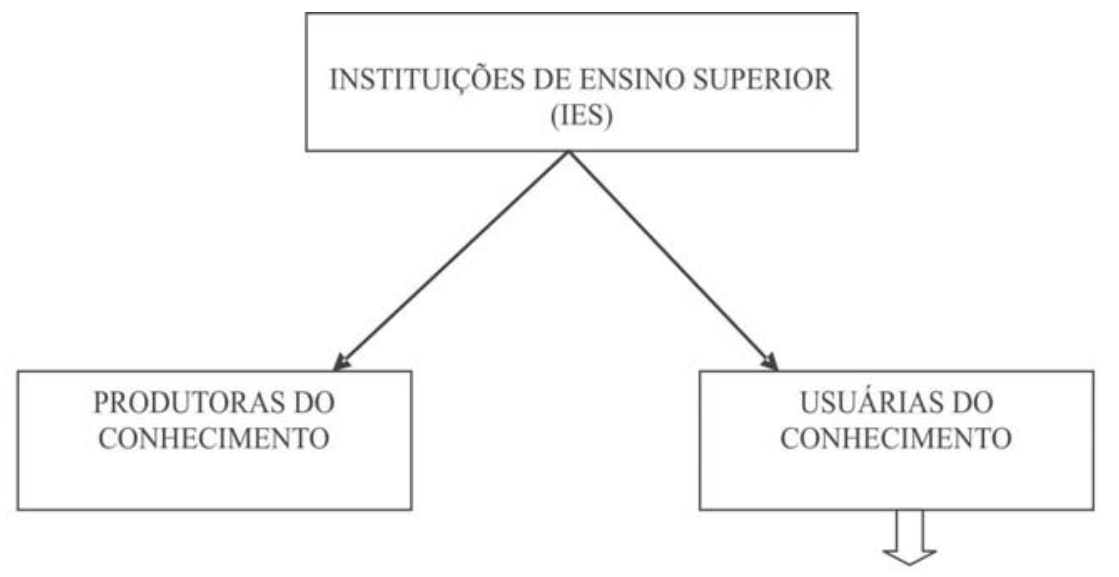

Precisam gerenciar estrategicamente seus recursos, de forma a garantir sua existência enquanto organizações empresariais.

Figura 1: IES como produtoras e usuárias do conhecimento.

Fonte: Elaborada pelos autores. 
O objetivo que se pretende alcançar com o desenvolvimento deste estudo é debater uma metodologia de como se pode promover a discussão do projeto pedagógico de um curso de graduação, integrando toda a comunidade acadêmica, fazendo com que cada docente perceba sua participação na construção do profissional que se pretende formar.

A principal justificativa para a realização deste estudo é o fato de que dois de seus autores participaram de três reformas curriculares realizadas no Curso de Administração ministrado pela Universidade a que estão vinculados. Observaram que vários debates são realizados por ocasião da discussão do projeto pedagógico, mas, na época da implantação, o corpo docente parece perder a noção do todo planejado para o curso. Assim, esquecem o perfil de profissional que se pretende atingir $e$, ainda pior, perdem a conexão de sua disciplina com as demais, passando a impressão de que o Curso esteja sendo ministrado sem uma concatenação entre elas. Os autores acreditam que, partindo do testemunho do esforço institucional na busca de uma participação e maior integração de todos em torno do entendimento e implantação do projeto pedagógico do Curso de Administração, possam oferecer à comunidade acadêmica uma ferramenta que auxilie nessa problemática comum a todo gestor de IES.

No item 2 deste artigo, destacam-se aspectos de aprendizado organizacional e de motivação que envolvam mudança curricular numa Instituição de Ensino. É importante que se saliente o papel do coordenador do curso no desenvolver do processo.

No item 3, será apresentado o referencial teórico que fundamentará o estudo, destacando, no item 4, sua metodologia. No item 5, está a proposta do estudo e, no 6, as considerações finais.

\section{Processo de Aprendizado Organizacional num Processo de Mudança Curricular}

Um processo de mudança curricular exige análise dos paradigmas estabelecidos internamente nas organizações. Toda instituição tem seus paradigmas cristalizados e, para haver alguma alteração, principalmente no tocante a conteúdos a serem ministrados, é preciso um preparo muito paciente e perseverante para que o objetivo buscado seja alcançado. 
Maria da Graça Pitiá Barreto • Eduardo Fausto Barreto • João Marcelo Pitiá Barreto

Destaca Senge (1997) que

[...] as principais instituições de nossa sociedade são orientadas para o controle e, não para a aprendizagem, recompensando os indivíduos por fazerem coisas ditadas por outros e não por cultivar sua curiosidade e impulso natural por aprender.

Essa afirmativa de Senge é importante porque destaca o esforço gerencial em manter a organização sob controle, impedindo a manifestação da criatividade.

Em se tratando de Instituições de Ensino, essa afirmativa pode-se constituir numa "faca de dois gumes", como popularmente se usa falar quando uma atitude pode provocar duas consequências. Ora, uma IES precisa ter certo controle sobre o que se está ministrando em sala de aula para conhecer se o conteúdo programático está sendo seguido. O risco desse controle pode ser a acomodação do professor, que não encontrará tempo para inovar e atualizar o conteúdo a ser ministrado.

Há necessidade, contudo, de que seja incentivado no seio das IES a curiosidade e o impulso natural por aprender, destacado por Senge. É importante que uma organização produtora de conhecimento, como o é uma Instituição de Ensino, motive sua comunidade acadêmica a repensar seus paradigmas. Quando se propõe a preparar novos profissionais, seu perfil precisa refletir as necessidades da sociedade. Do que adianta formar novos profissionais com atributos defasados?

A realidade atual é a base de estruturação do curso que se pretende organizar para ser oferecido aos alunos. Logicamente, até pelas dificuldades que se enfrenta ao reestruturar um curso, é conveniente que o projeto pedagógico do curso busque preparar o estudante para o momento atual que o profissional irá enfrentar, mas já abranja as perspectivas de evolução da realidade, dentro da visão estabelecida pela Instituição. Assim, os diretores acadêmicos ou os coordenadores de curso liderariam o processo de discussão $e$ atualização do curso dentro do princípio da tensão criativa, como defendido e denominado por Senge (1997).

Esse princípio está ilustrado na Figura 2, onde se apresentam mãos tensionando um elástico. $\mathrm{O}$ significado dessa ilustração é que a liderança institucional buscará motivar a comunidade na busca da visão almejada, par- 


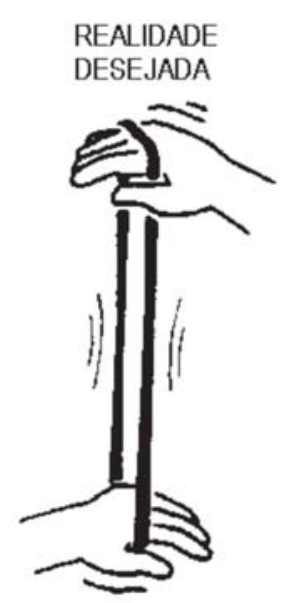

REALIDADE ATUAL

Figura 2: O princípio da tensão criativa.

Fonte: Starkey (1997, p. 346)

tindo da realidade atual, estruturando-se internamente para deixar eclodir ideias que conduzam ao estabelecimento do processo de aprendizado contínuo.

Esse processo de aprendizado incentiva a Instituição a adaptar-se à evolução da ciência observada. Então, no desenvolvimento da adequação de um curso e para que se consiga a participação, o entendimento e a contribuição de cada integrante organizacional, a utilização de ferramentas gerenciais, já desenvolvidas e divulgadas no âmbito da ciência da administração, é fundamental para a consecução do objetivo pretendido.

No próximo item, será discutido o resultado das pesquisas de Kaplan e Norton desenvolvidas durante o período de 1990 a 1996 que serviram de base para a elaboração de suas três obras referendadas neste estudo, base para a análise e proposição de ações sugeridas neste artigo.

\section{Fundamentação Teórica}

Em 1990, Kaplan e Norton, preocupados em medir o desempenho organizacional, iniciaram uma pesquisa envolvendo várias empresas. Observaram com o desenvolvimento desse estudo que "os relatórios financeiros tradicionais não forneciam fundamentos para a mensuração e gestão do valor criado pelo aumento das habilidades dos ativos intangíveis da organização" (KAPLAN; NORTON, 2004, p. VII). 
Desse projeto de pesquisa, emergiu o conceito do Balanced Scorecard, buscando, além de preservar os indicadores financeiros que expunham os resultados das iniciativas já adotadas, levar em consideração indicadores nãofinanceiros, sob as perspectivas: (1) clientes; (2) processos internos; e (3) aprendizado e crescimento. Esses indicadores mostravam-se de grande importância porque representavam o sustentáculo da organização no futuro. Sua visualização em grupos de perspectivas é útil na identificação dos fatores básicos que vão sendo construídos para que se consiga atingir o fim almejado.

Nos quatro anos seguintes, os pesquisadores continuaram acompanhando o desempenho das primeiras empresas adeptas do sistema, e se admiravam com o desempenho extraordinário que as organizações vinham atingindo em tão pouco tempo. Ao buscarem as razões dessa evolução, os pesquisadores constataram, junto aos executivos, que dois aspectos foram os responsáveis: alinhamento e foco (KAPLAN; NORTON, 2004, p. IX).

Com a continuidade de seus estudos, Kaplan e Norton descobriram que, ao iniciar um projeto, antes mesmo de decidir o que medir, os executivos precisavam definir quais eram seus objetivos. Precisavam declarar expressamente suas intenções nas quatro perspectivas do Balanced Scorecard. Os gestores foram estimulados a expor seus objetivos e declarar como mediriam o alcance de suas metas. Dessa forma, a seleção dos indicadores tornou-se mais simples.

Com o foco nos objetivos, os pesquisadores conseguiram outro avanço: interligar os objetivos com relações de causa e efeito. Ao relacionarem os objetivos com as quatro perspectivas do Balanced Scorecard, os executivos começaram a uni-los com setas. A rede de relações de causa e efeito explícita entre os objetivos deu origem ao diagrama que se chamou Mapa Estratégico.

O Mapa Estratégico mostrou-se tão importante para as organizações como se tinha mostrado o Balanced Scorecard. Então, os autores criaram um Mapa Estratégico genérico que pudesse ser útil a qualquer tipo de organização, possibilitando-lhes a adaptação a sua realidade. Surgiu, dessa forma, o terceiro livro dos autores que eles intitularam de Mapas Estratégicos: Convertendo ativos intangíveis em resultados tangíveis lançado em 1996.

$\mathrm{O}$ que os autores procuram expor é que os executivos precisam ter clareza dos objetivos que pretendem atingir e de como poderão medir o sucesso de sua empreitada, para construírem sua rede de relações de causa e efeito. Apesar do raciocínio desses autores ter sido construído na tentativa de 
auxiliar as organizações no alcance das metas empresariais, avaliadas pelo lucro projetado, e pela satisfação do acionista, motivado pelo incremento de valor proporcionado, a metodologia criada por Kaplan e Norton pode ser adaptada a qualquer objetivo institucional.

$\mathrm{Na}$ continuidade de seus estudos e analisando casos de sucesso e de fracasso de organizações, Kaplan e Norton entrevistaram gerentes que citaram a implementação da estratégia como o fator mais importante na avaliação da gerência e da corporação. A forma de implementação da estratégia passou a ser um indicador importante do desempenho da empresa e de seus gestores. Passou-se a valorizar a capacidade de executar a estratégia, mais do que a elaboração da estratégia em si.

Surge, então, o questionamento: será que o maior problema das empresas é uma má estratégia ou uma má gestão da estratégia? Kaplan e Norton perceberam, com índices de fracasso na faixa de $70 \%$ a $90 \%$, que investidores sofisticados chegaram à conclusão de que a execução é mais importante do que a visão (KAPLAN; NORTON, 2000, p. 11).

Nesse ponto, merecem destaque os papéis fundamentais da liderança realçados por Senge (1997, p. 347) para uma organização voltada para o aprendizado continuo: projetista, professor e regente. Dentro dessa terminologia:

a) O líder projetista estaria coordenando o processo de elaboração da estratégia. "O segredo não está em obter a estratégia certa, mas sim em promover o pensamento estratégico" (MINTZBERG apud SENGE, 1997, p. 349).

b) Como professor, o líder não estaria incentivando o exercício de seu autoritarismo, mas estaria ajudando as pessoas a adquirirem visões da realidade que sejam mais precisas e, assim, verem novas possibilidades para influenciar o futuro.

c) O papel de regente é mais sutil que os anteriores. Envolve a operação em dois níveis: regências das pessoas que lidera e regência do propósito ou missão maior que sustenta o empreendimento. Então, a implantação de uma estratégia requer uma coordenação e adequação organizacional com esse fim.

No intuito de ajudar a consecução de uma gestão eficaz e eficiente da estratégia, Kaplan e Norton criaram os cinco princípios de uma organização focali- 
zada na estratégia, os quais, se forem seguidos, ajudarão as empresas a atingirem resultados extraordinários. A Figura 3 destaca esses cinco princípios.

Os princípios surgiram da ideia de fazer a empresa ter alinhamento $e$ foco. Buscaram identificar de que maneira o foco propicia o desempenho notável. Chegaram à conclusão de que uma estratégia bem elaborada e bem compreendida é capaz de produzir avanços extraordinários não-lineares no desempenho, por meio da convergência e da consistência dos recursos limitados da organização (KAPLAN; NORTON, 2000, p. 18).

Na Figura 3, podem-se ver os princípios norteadores como pilares que sustentam a organização orientada para a estratégia. Sem eles, a empresa e seus objetivos ruiriam, desalinhando o alcance dos resultados almejados.

\section{PRINCIPIOS DAS ORGANIZAÇÕES FOCALIZADAS NA ESTRATÉGIA}

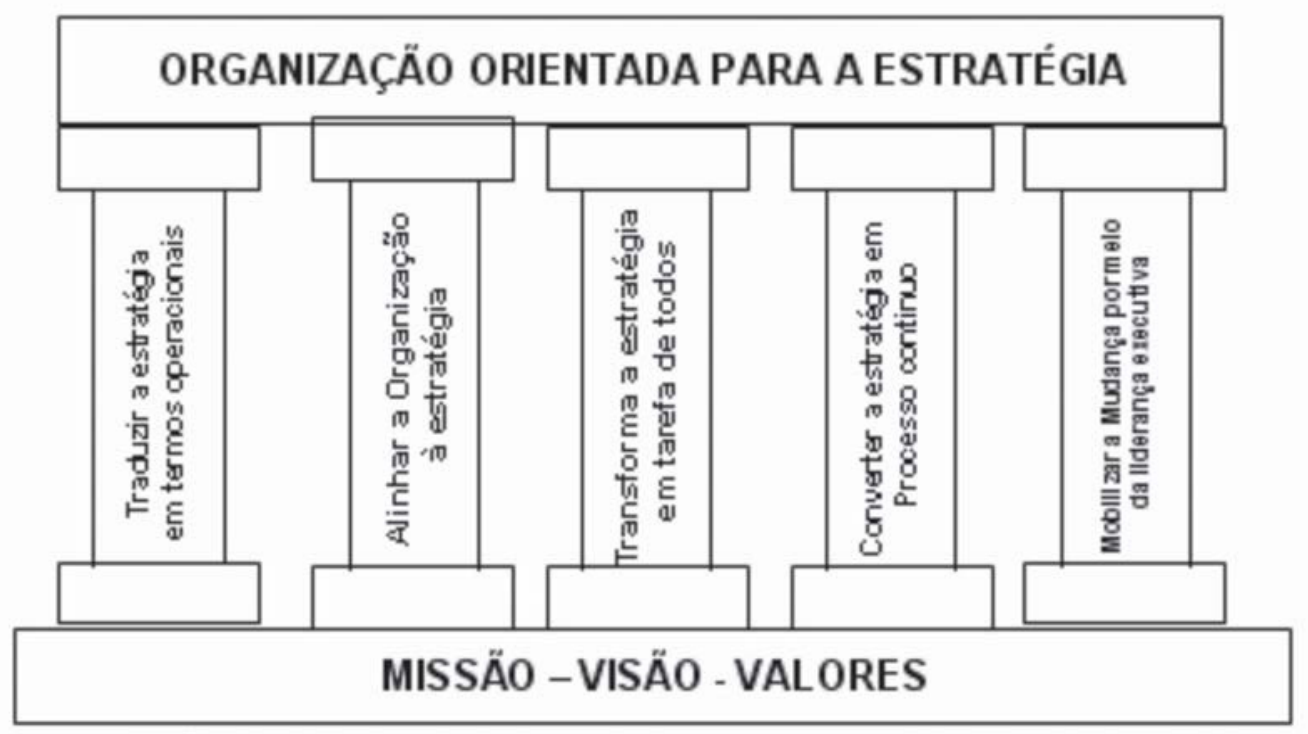

Figura 3: Princípios das Organizações focalizadas na Estratégia. Fonte: Adaptada de Kaplan e Norton (2005).

Observa-se, nessa figura, que os princípios estão sedimentados na missão, na visão e nos valores defendidos pela organização. A empresa analisará sua missão e, junto com seus valores, criará uma visão. Eles serão a base 
para os cinco pilares ou os cinco princípios que serão seguidos por uma organização alinhada à estratégia. A estratégia elaborada para ser bem implementada estará alicerçada nessas dimensões na busca dos objetivos pretendidos.

\section{$1^{\circ}$ passo: transformar a estratégia em termos operacionais.}

Antes de construir o Mapa Estratégico é preciso analisar qual é o tipo de negócio (organização privada, pública ou uma ONG), pois para cada uma existirão particularidades que devem ser analisadas corretamente. Uma vez definida a estratégia, busca-se criar um referencial geral para a sua descrição $e$ implementação, que Kaplan e Norton julgaram tão úteis quanto os referenciais utilizados pelos gerentes financeiros - demonstração de resultado, balanço patrimonial, demonstração do fluxo de caixa - para fins de planejamento financeiro e de elaboração de relatórios de desempenho. Esse novo referencial passou a ser chamado Mapa Estratégico.

\section{$2^{\circ}$ passo: alinhar a organização à estratégia.}

$\mathrm{Na}$ implementação do $2^{\circ}$ princípio, surge um componente novo: a sinergia. A sinergia é a meta mais abrangente do projeto organizacional. As organizações se compõem de numerosos setores, unidades de negócio e departamentos especializados, cada um com sua própria estratégia. Para que o desempenho organizacional seja superior à soma das partes, as estratégias individuais devem ser conectadas e integradas. A corporação define as conexões esperadas para a criação da sinergia e assegura a efetiva ocorrência dessas conexões. (KAPLAN; NORTON, 2000, p. 22).

\section{$3^{\circ}$ passo: transformar a estratégia em tarefa de todos.}

Kaplan e Norton, no desenvolvimento dos seus estudos, observaram que os executivos, ao adotarem o Balanced Scorecard, não tinham condições de implementar a estratégia sozinhos e, para tal, precisavam da contribuição de todos na organização. Perceberam, então, que esses líderes se deparavam com uma nova problemática: como difundir a estratégia a partir da sala dos conselhos para as bases operacionais e, assim, para as linhas de frente das atividades cotidianas e dos serviços aos clientes? 
Maria da Graça Pitiá Barreto • Eduardo Fausto Barreto • João Marcelo Pitiá Barreto

$4^{\circ}$ passo: converter a estratégia em processo contínuo.

Para a maioria das organizações, o processo gerencial se desenvolve em torno do orçamento e do plano operacional. A integração do Balanced Scorecard com os processos de planejamento e orçamento mostrou-se crítica para a organização focalizada na estratégia. "Com os orçamentos funcionando como principal ferramenta de controle das organizações, a atenção gerencial se concentra na consecução das metas financeiras de curto prazo" (KAPLAN; NORTON, 2000, p. 291). Então, apresenta-se uma dicotomia: a preocupação com a estratégia (longo prazo) com o controle orçamentário de curto prazo.

Com o decorrer do tempo, a partir da implementação do Balanced Scorecard, as relações de causa e efeito passam a ser mais bem compreendidas e pode ser desenvolvido um processo de aprendizado e adaptação da estratégia. Todo esse processo vai exigir a implementação do $5^{\circ}$. princípio basilar para uma organização orientada para a estratégia que é a atuação vibrante de uma liderança executiva.

\section{$5^{\circ}$ passo: mobilizar a mudança por meio de liderança executiva.}

A implementação de novas estratégias exige mudanças em grande escala. Após a deflagração da mudança, os executivos estabelecem um processo de governança para orientar a transição. Nessa etapa, é importante a criação de equipes estratégicas, a realização de reuniões coletivas e a promoção da comunicação aberta com toda a organização.

A conversão da estratégia em processo contínuo vai exigir o estabelecimento da rede de relações de causa e efeito evidenciada no Mapa Estratégico.

Para entender o conceito e a importância dos Mapas Estratégicos para o alcance dos resultados estratégicos esperados, considera-se conceituação de Herrero Filho (2005, p. 201): "Um instrumento para dar forma, narrar, visualizar, comunicar, alinhar os participantes da organização em torno da estratégia competitiva".

O Mapa Estratégico foi criado buscando atender alguns aspectos que foram observados nas pesquisas desenvolvidas por Kaplan e Norton (2005, p. 35), tais como:

a) Não existia uma maneira consistente de apresentar a estratégia.

b) Não se dispunha de método amplamente aceito para descrever a estratégia. 
c) Não se podia representar e visualizar as relações de causa e efeito entre os componentes da estratégia de uma organização.

A estruturação de um Mapa Estratégico, como se pode observar na Figura 4, é uma evolução das quatro perspectivas do Balanced Scorecard, acrescentando uma segunda camada de detalhes que ilustra a dinâmica temporal da estratégia, além de adicionar um nível de detalhe que melhora a clareza e o foco.

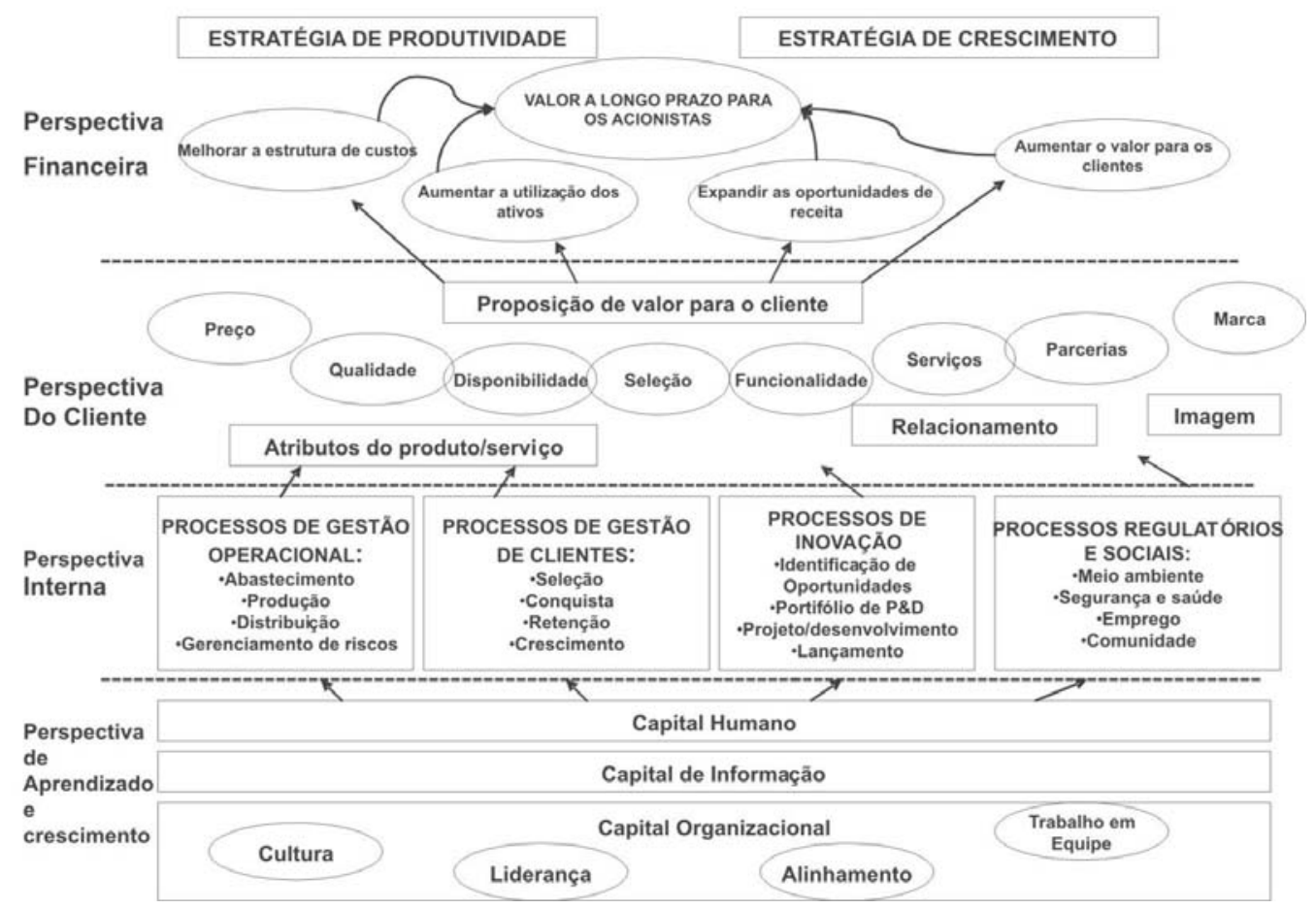

Figura 4: Mapa Estratégico Genérico.

Fonte: Kaplan e Norton (2004, p. 11).

Esse modelo genérico como o nome mesmo diz é geral e pode ser adaptado em diferentes organizações. Assim, esse modelo modifica-se, a depender da necessidade ou do ramo de atuação da empresa, e podem ser acrescentadas ou retiradas perspectivas. Por exemplo, empresas que lidam diretamente com a natureza estariam acrescentando uma perspectiva ambiental. Empresas sem fins lucrativos podem colocar a perspectiva financeira na parte de baixo do Mapa Estratégico, pois não é o objetivo principal da organiza- 
Maria da Graça Pitiá Barreto • Eduardo Fausto Barreto • João Marcelo Pitiá Barreto

ção gerar ganhos financeiros, mas dispor de recursos para o desenvolvimento das ações organizacionais.

Então, na construção do Mapa Estratégico, é necessário analisar as particularidades de cada tipo de negócio (organização privada, pública ou uma ONG), pois cada uma tem características que devem ser refletidas para o êxito de uma implantação de um Mapa Estratégico eficiente e eficaz.

É esta orientação que se pretende adotar neste trabalho: adaptar-se a metodologia do mapa estratégico à construção e implantação de um projeto pedagógico de um Curso de Administração.

\section{Metodologia}

Este estudo, dentro dos fins a que se propõe, pode ser classificado: (1) como um estudo exploratório, porque parece não haver estudos que se proponham a adaptar os mapas estratégicos criados por Kaplan e Norton a uma gestão de um curso de graduação; e (2) como estudo descritivo, porque apresenta a realidade de uma unidade de uma universidade pública.

Em relação aos meios, foi feito um estudo de caso de um curso de graduação em administração dessa universidade. Os procedimentos descritos neste estudo refletem as discussões que estão sendo travadas no interior da unidade responsável pela oferta do curso à sociedade.

Os dados primários utilizados são reais, extraídos da universidade foco do estudo, e serão trabalhados a partir de dados secundários produzidos com a consulta a sites e referencial teórico.

A Escola de Administração dessa universidade já passou por duas reformas curriculares e, atualmente, está adaptando o Curso de Administração às exigências das Diretrizes Curriculares do MEC. Observou-se, nas outras iniciativas, que (1) o corpo docente e o discente participaram das discussões da estruturação dos projetos pedagógicos anteriores, mas pareceram perder, no processo de implantação, a noção do todo; (2) os professores pareceram não entender a importância de sua disciplina no contexto de formação do profissional pretendido. 


\section{Proposição do Estudo}

Objetivando criar uma sinergia em torno da construção do futuro profissional com a participação e entendimento da comunidade acadêmica da unidade estudada, neste item, estão expostas as adaptações da metodologia de Kaplan e Norton que estão sendo realizadas nas discussões e implantação do Curso de Administração da Escola estudada. Neste artigo, admite-se a possibilidade de ajustamento do modelo às várias realidades e objetivos organizacionais.

Os seguintes aspectos destacados por Kaplan e Norton foram a motivação para elaborar-se um Mapa Estratégico do Curso de Administração:

a) Não existia uma maneira consistente de apresentar a estratégia - em decorrência dos problemas identificados nas experiências curriculares anteriores, observou-se que uma visualização da estruturação do curso num Mapa Estratégico poderia auxiliar na compreensão do todo e na contribuição de cada disciplina ou atividade planejada na formação do profissional pretendido.

b) Não se dispunha de método amplamente aceito para descrever a estratégia - a comunidade acadêmica estava acostumada a visualizar o curso em semestres de formação. Os semestres relacionavam, de forma estanque, todas as disciplinas com seus prerrequisitos.

c) Não se podia representar e visualizar as relações de causa e efeito entre os componentes da estratégia de uma organização - com a mesma justificativa do item anterior, a semestralidade expõe aos alunos e professores a distribuição das disciplinas ao longo do curso, mas não se pode visualizar qual o efeito que cada uma poderia provocar na formação do estudante.

Buscou-se, dessa forma, traduzir os princípios estabelecidos por Kaplan e Norton (2000) à realidade de uma instituição de ensino: 
$1^{\circ}$ passo: transformar a estratégia em termos operacionais.

É importante que toda a comunidade acadêmica tenha familiaridade com alguns termos essenciais no desenvolvimento de um curso de graduação, tais como:

a) Diretrizes Curriculares - referências para elaboração, revisão, implementação, monitoração e avaliação permanente do Projeto Pedagógico do Curso, o qual deve ser de construção coletiva, envolvendo todos os agentes que participam do processo educativo, sendo respeitado por todas as Instituições de Ensino Superior;

b) Projeto pedagógico - plano que visa assegurar a flexibilidade, a diversidade, a autonomia, a interdisciplinaridade, a contextualização e a identidade do Curso;

c) Perfil do profissional - características do profissional que se quer formar;

d) Competências - se constituem num conjunto de conhecimentos, atitudes, capacidades e aptidões que habilitam alguém para o desempenho da profissão;

e) Habilidades - se ligam a atributos relacionados não apenas ao saber-conhecer, mas ao saber-fazer, saber-conviver e ao saber-ser;

f) Disciplinas - conjunto de atividades relacionadas a uma área de interesse importante em todo o projeto;

g) Atividades - são ações que são desenvolvidas durante o curso e que produzem um resultado significativo no contexto do projeto pedagógico; $e$

h) Atividades complementares - são componentes curriculares que possibilitam o reconhecimento, por avaliação, de habilidades, conhecimentos e competências do aluno, inclusive adquiridas fora do ambiente escolar, incluindo a prática de estudos e atividades independentes, transversais, opcionais, de interdisciplinaridade, especialmente nas relações com o mundo do trabalho e com as ações de extensão junto à comunidade. 
Todos os integrantes da comunidade precisam ter claros esses conceitos. Como, coloquialmente, se diz, precisam falar a mesma língua para que se possa discutir a forma de conseguir incluí-los na estruturação do curso.

\section{$2^{\circ}$ passo: alinhar a organização à estratégia.}

Exige um comportamento sinérgico na instituição. A sinergia é a meta mais abrangente do projeto organizacional. Todos os membros da comunidade precisam entender o que a Instituição pretende com seu projeto pedagógico e, compreendendo sua importância e responsabilidade no alcance do pretendido, atuar de forma a contribuir para o clima de integração institucional.

$3^{\circ}$ passo: transformar a estratégia em tarefa de todos.

Esse princípio pode ser considerado uma consequência do anterior. $\mathrm{Na}$ medida em que se consegue uma sinergia organizacional, percebe-se que o gestor acadêmico e o coordenador do curso não têm condições de implementar, sozinhos, o projeto pedagógico e, para isso, precisavam da contribuição de todos na organização.

\section{$4^{\circ}$ passo: converter a estratégia em processo contínuo.}

Uma adaptação desse passo a uma discussão e implantação curricular, envolve a discussão departamental dos conteúdos programáticos no esforço de que, com o decorrer do tempo e a partir da implementação das modificações estruturadas, as relações de causa e efeito passem a ser mais bem compreendidas, e se possa conduzir um processo contínuo de aprendizado em busca do perfil do profissional pretendido.

\section{$5^{\circ}$ passo: mobilizar a mudança por meio de liderança executiva.}

A implementação de um novo currículo exige mudanças em grande escala. Nessa etapa, as equipes estratégicas sugeridas por Kaplan e Norton (2000) podem ser interpretadas como: os departamentos em que estão vinculadas as disciplinas, através dos quais se poderá discutir o conteúdo necessário para transformar as ementas em conteúdos programáticos e, também, poderá ser observada a implantação dos ajustes sugeridos. A realização de reuniões coletivas promovidas junto a toda a comunidade acadêmica 
poderá abrir um processo de comunicação com toda a instituição, $e$ as dificuldades e entraves à implementação das mudanças sugeridas poderão ser entendidos e sanados.

A apresentação do Mapa Estratégico do Curso tem integrado todo o processo de discussão curricular na Escola de Administração estudada, facilitando a visualização das perspectivas de formação do estudante e a contribuição de cada disciplina para o alcance do profissional pretendido. A Figura 5 expõe o Mapa Estratégico do Curso de Administração utilizado nesses debates.

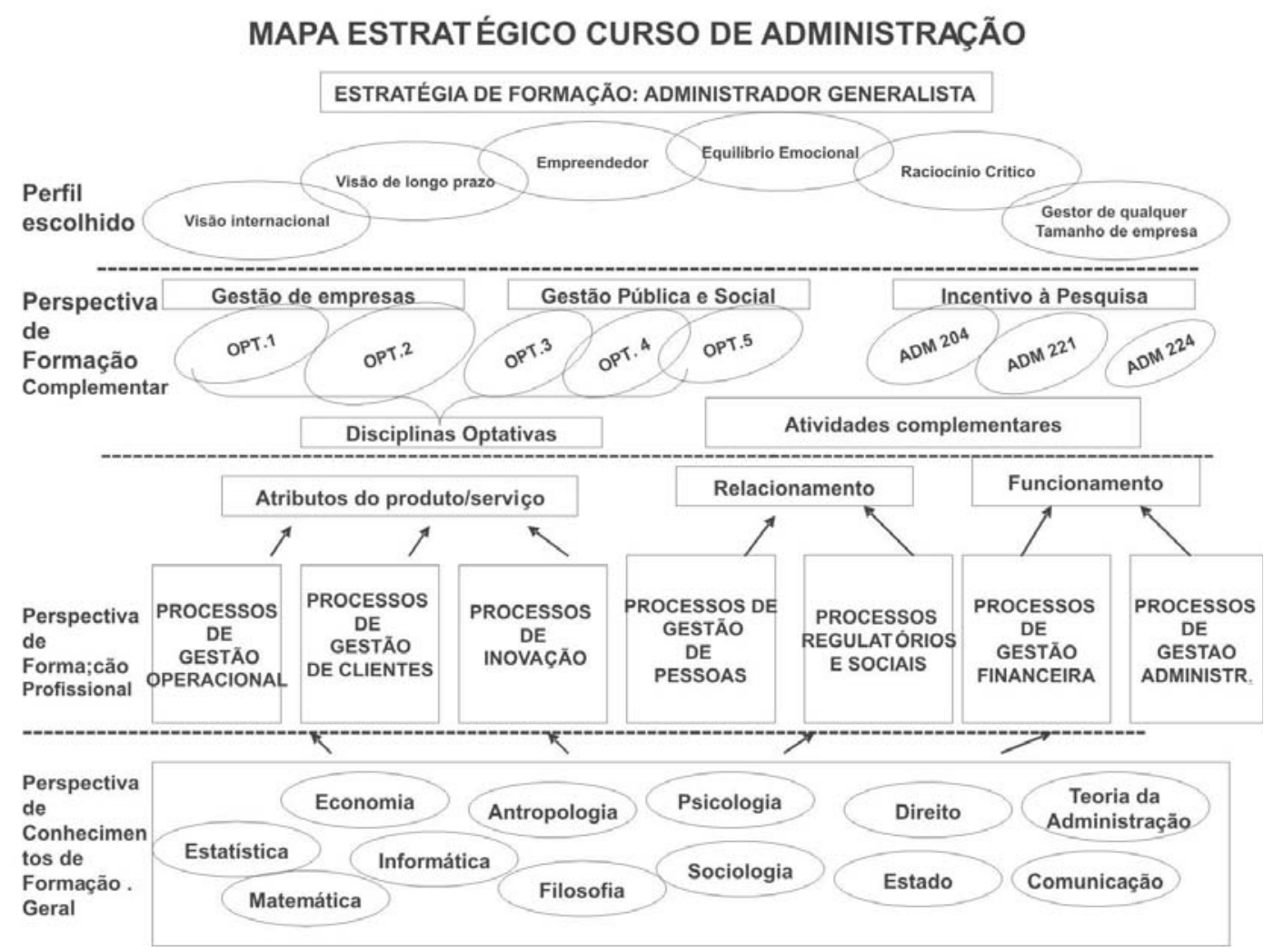

Figura 5: Mapa Estratégico do Curso de Administração.

Fonte: Adaptada de Kaplan e Norton (2004). 
Com a utilização da ferramenta do Word do Hiperlink, se pode clicar em cada elipse ou retângulo integrante do diagrama e, com isso, visualizar a ementa e o conteúdo programático que, atualmente, estão sendo ministrados. Com essa ação, é possível: (1) analisar se esse conteúdo é adequado, ou se precisa ser modificado; (2) se as disciplinas atuais atendem ou se precisam ser criadas outras para atender ao perfil profissiográfico definido; e (3) se esse conteúdo vinha integrando o conjunto de disciplinas existentes.

No topo da Figura 5, está explícito o perfil do profissional que se quer formar: administrador generalista com os atributos: visão internacional e longo prazo, empreendedor, gestor de organizações de qualquer tamanho e que possua equilíbrio emocional e raciocínio crítico. Para que esse perfil seja alcançado, há as disciplinas de formação geral, as de formação profissional e as de formação complementar.

Na perspectiva de base, estão as disciplinas que transmitem os conhecimentos de formação geral, necessários para que o aluno se fundamente para apreender os conhecimentos de formação profissional, que integram a perspectiva imediatamente superior. Essas duas perspectivas são compostas de disciplinas obrigatórias, pois a perspectiva de formação complementar está composta por disciplinas optativas, pela disciplina ADM 221 (Estágio Curricular) e por aquelas planejadas para despertar no aluno o interesse pela pesquisa acadêmica (é o caso das disciplinas ADM 204 - Pesquisa aplicada à Administração - e ADM 224 - Monografia). Essa Escola tem condições de proporcionar uma formação complementar com duas ênfases: gestão de empresa e gestão pública e social e, portanto, os alunos poderão escolher em complementar a sua formação com disciplinas optativas que ofereçam esses conteúdos.

Exemplificando-se a utilização do hiperlink na análise dos conteúdos versus disciplinas e/ou atividades, expõe-se na Figura 6 um retângulo no qual se pode analisar o conteúdo de algumas disciplinas da área financeira e verificar sua adequação na perspectiva do profissional que está sendo formado: 


\section{PROCESSOS \\ DE \\ GESTÃo \\ FINANCEIRA}

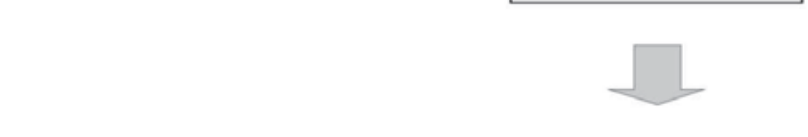

\section{PROCESSOS DE GESTÃO \\ FINANCEIRA}

- Gerir a estrutura de custos organizacionais

- Aumentar a utilização dos ativos.

- Expandir as oportunidades de receitas

- Diminuir o grau de endividamento

- Buscar aumentar o valor para os acionistas

- Identificar as melhores oportunidades de investimentos

- Analisar a situação econômicofinanceira das organizações
- Disciplinas associadas:

Administração Financeira I

Administração Financeira II

Gestão de Custos I

Seminário sobre temas Específicos de Administração Financeira (optativa)

Gestão de Custos II (optativa)

Auditoria I (optativa)

Figura 6: Exemplo de análise do conteúdo de processos de gestão financeira com o auxílio do hiperlink.

Fonte: Dados do estudo.

A utilização do Mapa Estratégico pode ser útil, também, para esclarecer à comunidade acadêmica as habilidades que se pretende estimular nos futuros profissionais. A Figura 7 apresenta grandes setas que perpassam as várias perspectivas, significando as habilidades buscadas e que serão desenvolvidas ao longo de todo o curso.

A Pesquisa Nacional 2006, realizada pelo Conselho Federal de Administração, evidenciou que a sociedade espera um profissional com a habilidade de enxergar a organização como um sistema composto por partes que precisam interagir para o alcance dos objetivos defendidos. Por isso, inseriuse a seta identificada como visão sistêmica da organização. Nessa pesquisa, 
foi identificada outra habilidade do administrador que é a capacidade de articular não só as suas ideias como ações entre componentes do contexto organizacional e ambiental onde a instituição atua.

Não se pode conceber formar um administrador que não tenha liderança para atuar, conduzindo os integrantes organizacionais na busca das metas estabelecidas. Outra habilidade que precisa ser estimulada é a do aprendizado contínuo. Se, no futuro, o administrador precisará buscar continuamente seu aperfeiçoamento, é importante que ele seja motivado nessa busca. As atividades complementares têm um papel fundamental nesse incentivo.

A valorização de parcerias, a prática de ações éticas e o respeito às diferenças são outras habilidades que, para serem desenvolvidas, não pertencem a um componente curricular específico, mas representam atitudes que precisam ser cobradas e praticadas no meio acadêmico.

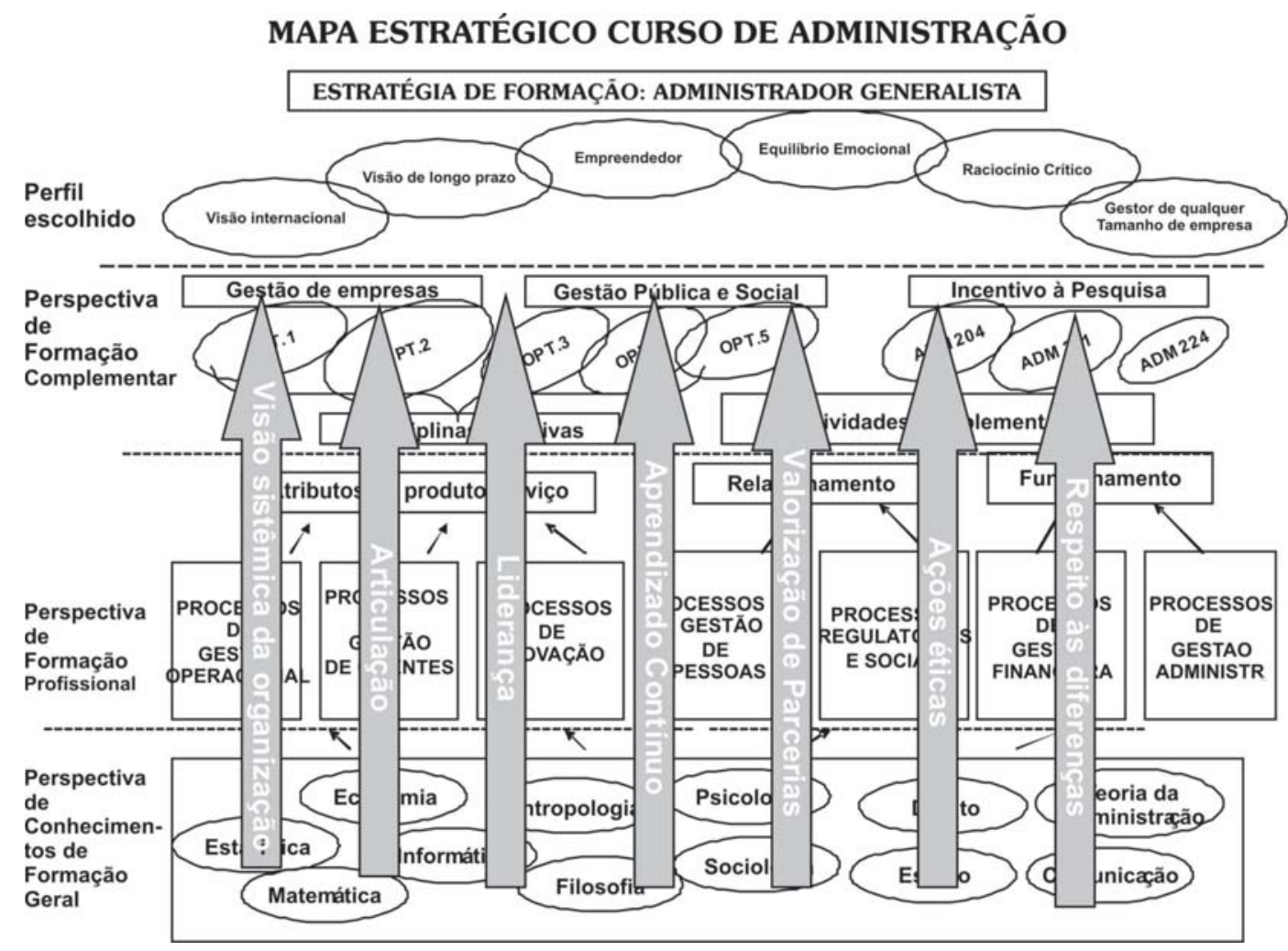

Figura 7: Mapa Estratégico de um Curso de Administração - habilidades pretendidas.

Fonte: Dados do estudo. 
Maria da Graça Pitiá Barreto • Eduardo Fausto Barreto • João Marcelo Pitiá Barreto

Essas habilidades, como todo o conteúdo programático, podem ser criticadas, modificadas, acrescentadas, enfim, ser submetidas à apreciação $e$ compreensão de todos os integrantes da instituição.

\section{Considerações Finais}

Este artigo vem comprovar como é importante a interação dos dois eixos estruturadores do conhecimento nas Universidades. A integração da experiência da graduação com os avanços na pesquisa motivados pelos estudos de pós-graduação é a origem deste estudo. Essas reflexões foram desenvolvidas a partir da experiência de dois professores que vêm presenciando reformas curriculares desenvolvidas na Escola de Administração onde atuam, e testemunhando a dificuldade de transmitir aos docentes o perfil do profissional que se quer formar e, mais ainda, fazê-los entender a sua contribuição no alcance desse perfil. Um jovem mestre, que discutiu os estudos estratégicos no seu Curso de Mestrado, motivou a adequação das teorias de Kaplan e Norton às discussões curriculares que, sempre, são travadas no interior das IES.

Acreditando que a Universidade é produtora do conhecimento e, também, usuária do saber produzido, buscou-se, com este artigo, adaptar a metodologia da elaboração do Mapa Estratégico, criado por Kaplan e Norton, para facilitar as discussões e implantação das modificações curriculares necessárias. As discussões realizadas no interior da organização estudada foram facilitadas pelo Mapa Estratégico do Curso de Administração, provocando um entendimento claro do perfil buscado e a interrelação das disciplinas $e$ atividades desenvolvidas na estrutura do curso.

Diante da facilidade de análise do curso estudado, recomenda-se a outros cursos que repitam a experiência, para que possam comprovar essa facilidade de diálogo com a comunidade acadêmica no entendimento e sugestões de melhoria para o curso dentro do perfil do profissional pretendido. 


\title{
The strategic map of a course of administration
}

\begin{abstract}
It seems the common problem is to plan a course of Administration, to create its educational project and implement it with the appropriate participation of the entire faculty. The question guiding this study is: How does the academic community participate in the drafting of the educational project and believe in the institutional context in search of work you want? The goal is to achieve with the development of this study, is to discuss a methodology of how to promote the discussion of the educational project of a course for graduation, integrating the entire academic community, so that each teacher understand their participation in the construction of professional to be formed. It was done a study exploratory, descriptive of the reality of a unit of a public university. The search strategy was to do a case study with primary data studied at the School of Management, where he sought to adapt the methodology of preparing strategic maps developed by Kaplan and Norton, the discussion and implementation of educational project in the Course of Administration taught by that unit.
\end{abstract}

Key-words: Strategic Map. Educational Project. Profile of Desired Professional.

\section{REFERÊNCIAS}

CONSELHO FEDERAL DE ADMINISTRAÇÃO. Pesquisa Nacional 2006. Brasília: CFA, 2006.

HARVARD Business Review. Liderança: os melhores artigos da Harvard Business Review. Rio de Janeiro: Elsevier, 2006.

HERRERO FILHO, Emílio. Balanced Scorecard e a gestão estratégica: uma abordagem prática. 7. ed. Rio de Janeiro: Elsevier, 2005.

HOOVER, John; VALENTI, Ângelo. Liderança compartilhada: como alinhar o que as pessoas fazem melhor com o que as empresas precisam. São Paulo: Futura, 2006. 
Maria da Graça Pitiá Barreto • Eduardo Fausto Barreto • João Marcelo Pitiá Barreto

KAPLAN, Robert S.; NORTON, David P. A estratégia em ação: Balanced Scorecard. 23. ed. Rio de Janeiro: Elsevier, 1997.

Elsevier, 2000.

Organização orientada para a estratégia. Rio de Janeiro:

- Mapas estratégicos: convertendo ativos intangíveis em resultados tangíveis. 8. ed. Rio de Janeiro: Elsevier, 2004.

KHUN, Thomas. The structure of scientific revolutions. 2nd. ed. Chicago: University of Chicago Press, 1970.

SENGE, Peter M. O novo trabalho do líder: construindo organizações que aprendem. In: STARKEY, Ken. Como as organizações aprendem: relatos do sucesso das grandes empresas. São Paulo: Futura, p. 342-375, 1997.

VERGARA, Sylvia Constant. Gestão de pessoas. 2. ed. São Paulo: Atlas, 2000 . 